\title{
Parallel sample processing using dispersive INtip micro-purification on programmable multichannel
} pipettes

\author{
Patrick A Kates', John J Tomashek', David A Miles'1 \& L Andrew Lee*,1
}

\begin{abstract}
Automation gives researchers the ability to process and screen orders of magnitude higher numbers of samples than manual experimentation. Current biomacromolecule separation methodologies suffer from necessary manual intervention, making their translation to high-throughput automation difficult. Herein, we present the first characterization of biomacromolecule affinity purification via dispersive solidphase extraction in a pipette tip (INtip). We use commercially available resin and compare efficiency with batch and spin column methodologies. Moreover, we measure the kinetics of binding and evaluate resin binding capacities. INtip technology is effective on, and scalable for, an automated platform (INTEGRA ASSIST). The results suggest that high-throughput biomolecular workflows will benefit from the integration of INtip separations.
\end{abstract}

\section{METHOD SUMMARY}

We have developed a pipette tip containing nickel-affinity resin that utilizes dispersive solid-phase extraction to purify histidinetagged proteins at high yields and purity. This tip has been employed on an automated device and can be scaled for high-throughput applications. The efficiency, capacity and affinity of these tips were tested with three proteins in bacterial cell lysates.

\section{KEYWORDS}

automation • chromatography $\cdot$ dispersive solid-phase extraction $\cdot$ high-throughput screening • INtip chemistry • purification

'Integrated Micro-Chromatography Systems, Inc., Irmo, SC, USA; *Author for correspondence: lee@imcstips.com

BioTechniques 68: 148-154 (March 2020) 10.2144/ btn-2019-0140
Over several decades, microscale protein purification techniques have been sorted into five basic approaches (Table 1), all premised on the same fundamental steps (Figure 1). Protein targets with an affinity tag are mixed with a functionalized surface to encourage specific binding. A wash step then removes nonspecifically bound or weakly bound contaminants. Finally, an elution step disrupts the tagsurface interaction, allowing for collection of a purified protein. The first method, batch extraction, involves mixing loose resin with liquid sample in a single vessel, followed by sedimentation, washing and elution of captured protein. The second method traps resin between filters in a spin column and passes liquid samples, washes and eluents through the resin by centrifugation. Less cumbersome than batch extraction, spin columns reduce the carryover of resin into subsequent steps. A third method, used mostly for high-throughput (HTP) applications, employs functionalized magnetic beads to separate the bound proteins from solution. A fourth approach, using resin packed in a pipette tip, is a miniaturized version of (bi)directional fast protein liquid chromatography. Used for over 30 years to purify DNA [1], more recently this approach has become popular for antibody purification [2].

These technologies vary in their processing mechanics, necessary hardware, and investment of operator time and expertise. In some instances, automated HTP systems can reduce operator input or minimize centrifugation, but to maintain consistent flow rates backpressure must be kept low, and to achieve high purity carryover between sample wells or wash steps must also be controlled. Combined, these limitations mean that none of the four purifi- cation methods listed above fully accommodates HTP automated affinity purification. Challenges with these four protein purification methodologies include limited throughput, sample carryover and automation incompatibilities (Table 1) [3,4]. To address these issues, we propose a fifth approach: dispersive solid-phase extraction (dSPE) in a pipette tip (INtip).

INtip technology has demonstrated accuracy and reproducibility for microscale purification [5]. Dispersal of resin maximizes exposed surface area, optimizing bimolecular reaction rates (Figure 1) [6]. A frit at the mouth of the tip stops resin from dispensing into sample wells, and a top barrier prevents liquid from aspirating into the pipette head [7]. Major applications of this technology have focused on small molecule cleanup and isolation, coupled with multiple detection methodologies [6,8-11]. Applications of dSPE are expanding; recent uses include detection of contaminating analytes in pork [7] and wine [12] and the extraction of urine catecholamines [13]. Recently, our lab has reported a fully automated method for the identification of phosphopeptides from cell lysate using INtip technology [14]. Much of the previous work with dSPE tips employed organic solvents to aid subsequent separations $[15,16]$. None of these studies, however, has demonstrated the use of dSPE for biomacromolecule purification from cell lysates.

Here, we report the first extensive exploration of a new pipette tip design containing a commercially available nickel-affinity resin. This INtip purification is designed for introductory-level automated platforms, such as ASSIST and ASSIST PLUS (INTEGRA Biosciences Corp., NH, USA), whose prices allow 


\section{BioTechniques}

smaller academic and industrial laboratories to embrace a previously out-ofreach technology-namely, automation. The principles explored in this article are widely applicable to other types of affinity resins, pipette tip types and automated platforms, suggesting widespread application in fields such as novel affinity-tag purification, dual-tagged protein purification, antibody purification and protein engineering for both academic and industrial laboratories.

\section{MATERIALS \& METHODS}

Chemicals \& reagents

Sodium chloride, N-2-hydroxyethylpiperazine-N'-2-ethanesulfonic acid (HEPES) and imidazole were purchased from Fisher Scientific (NH, USA) and used without further purification. $\mathrm{Ni}^{2+}$ Sepharose ${ }^{\mathrm{TM}}$ excel $(\mathrm{XL})$ and $\mathrm{Ni}^{2+}$ Sepharose $^{\mathrm{TM}} 6$ Fast Flow (FF) resins were purchased from $\mathrm{GE}$ Healthcare (IL, USA), diluted and stored in $20 \%$ ethanol at $4^{\circ} \mathrm{C}$. $\mathrm{His}_{6}$-tagged protein sequences for beta-glucuronidase (GusA), Dasher ${ }^{\circledR}$ green fluorescent protein (GFP) and arylsulfatase (PaS) were synthesized by ATUM (CA, USA), expressed in Escherichia coli and purified by column chromatography. Eppendorf ${ }^{\mathrm{TM}}$ 96-well Deepwell plates, and Eppendorf ${ }^{\mathrm{T} M}$ Protein LoBind Tubes were purchased from VWR International (PA,
USA) and Fisher Scientific, respectively.

\section{Batch extraction}

Comparative batch expression for sample binding was performed in 1.5-ml Eppendorf LoBind tubes. In each of three tubes, $100 \mu \mathrm{l}$ of $25 \%$ resin slurry was added to $825 \mu$ of equilibration buffer (50-mM HEPES, $\mathrm{pH}$ 7.5; $0.5-\mathrm{M} \mathrm{NaCl}$ ) and mixed on an Argos Technologies (IL, USA) RotoFlex for $1 \mathrm{~min}$. The tubes were centrifuged at $1000 \times g$ at room temperature for $1 \mathrm{~min}$. Supernatants were decanted manually with a pipette without disturbing the bed. The resin was washed twice with equilibration buffer and drained as before. To the equilibrated resin, $0.66 \mathrm{mg}$ of $\mathrm{His}_{6}$-GFP in equilibration buffer was added. The samples were mixed in the RotoFlex for different time periods. Intermittently, tubes were centrifuged to pellet resin, the protein content of the supernatants was measured by A280 on a NanoDrop ${ }^{\text {TM }} 2000$ (Thermo Fisher Scientific, MA, USA) and $e_{280}$ values were calculated from the amino acid content [17]. Free protein was plotted as a function of mixing time.

\section{INtip protein binding}

Binding kinetics were performed on an INTEGRA multichannel pipette. Protein content was monitored by absorbance at $280 \mathrm{~nm}$. Resin was equilibrated in the tip by three aspiration and dispense cycles of $800 \mu$ l equilibration buffer each. Liquid was fully dispensed before moving to the next well. The sample $(825 \mu \mathrm{l})$ contained target proteins at different concentrations in equilibration buffer. Protein was bound to the resin in a series of aspiration $(60 \mu \mathrm{l} / \mathrm{s})$ and dispense $(15 \mu \mathrm{l} / \mathrm{s})$ cycles. Each cycle included a 20-s delay after both aspiration and dispense. Each cycle took a total of $110 \mathrm{~s}$. Samples were taken to measure residual protein content at $0,1,2,3,4,5,7$, $10,15,20$ and 25 cycles. Bound protein was calculated by subtracting protein remaining in the sample well from the total at time zero. Bound protein was plotted as a function of cycles or time (seconds). Data were fitted with an exponential function where $Y_{0}$ is the initial protein amount in solution, $t$ is defined as time (s), and the $k_{\text {obs }}$ value $\left(\mathrm{s}^{-1}\right)$ is the observed rate constant (Equation 1). Two-site exponential association fits converged with single-site exponentials over the concentrations and times used. Initial rates of binding, based on the changes over the first four cycles, were calculated at each protein concentration to determine a bimolecular rate constant $\left(\mathrm{M}^{-1} \mathrm{~s}^{-1}\right)$ and an off rate $\left(\mathrm{s}^{-1}\right)$. All samples were run in triplicate.

$Y=Y_{0}^{*}\left(1-e^{-k_{o b s} t}\right)$

(Equation 1)

Table 1. Summary of various affinity chromatography purification techniques.

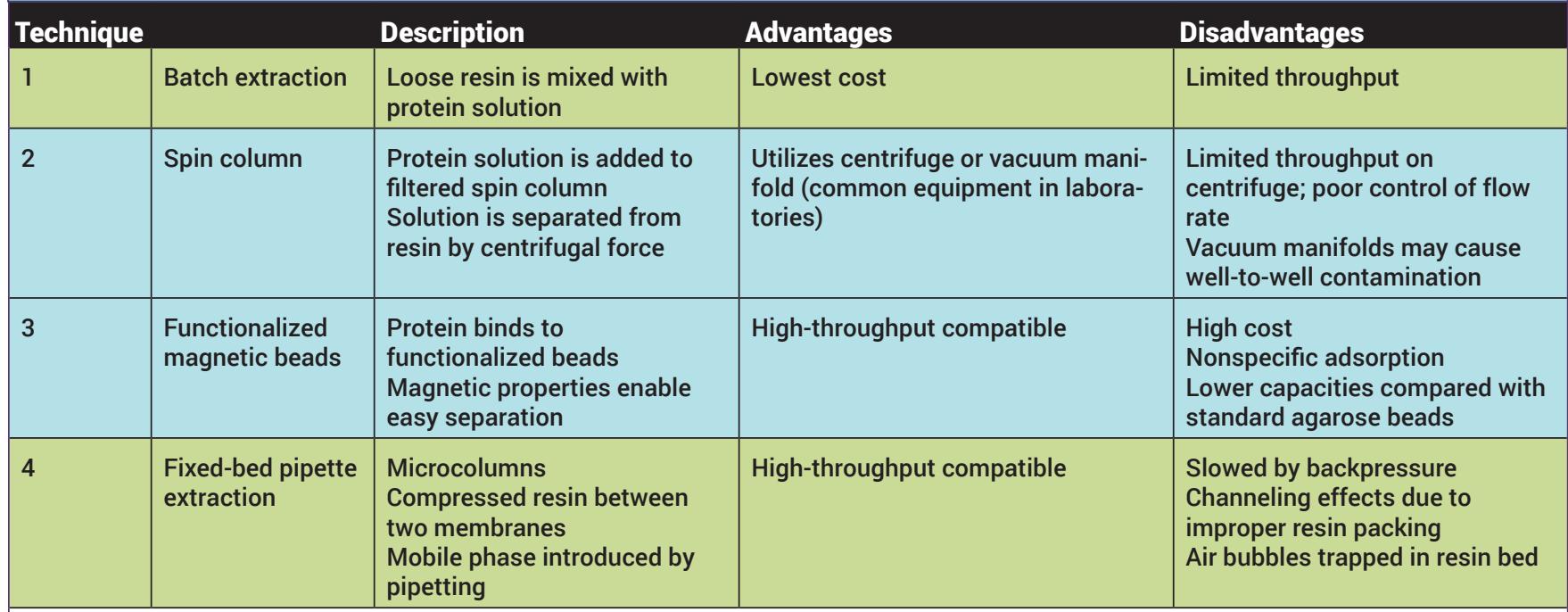

FPLC: Fast protein liquid chromatography; INtip: In a pipette tip. 
Figure 1. Graphical representation of five separation techniques. (1) A depiction of batch chromatography, where samples are loaded onto free resin, washed and eluted; centrifugation is required to separate resin from liquid. (2) A spin column is used to retain resin during the centrifugation steps, allowing for separation of resin and liquid. (3) Magnets are used to separate functionalized magnetic beads from the bulk medium. (4) In fixed-bed pipette extraction, a resin is fitted between two membranes, over which material is purified via bidirectional flow. (5) In dSPE, resin is freely mixed in solution via turbulent mixing. Resin is retained via a bottom membrane. Low backpressure allows for more rapid bidirectional flow than in the fixed-bed approach. Created with BioRender.com. dSPE: Dispersive solid-phase extraction.

\section{Elution optimization}

Effects of elution volume and cycle number were evaluated on an INTEGRA pipette. Protein in the equilibration buffer was bound to resin over 25 cycles as described for the INtip protein binding experiment. After 25 cycles, all liquid was blown out of the pipette by dispensing an additional $350 \mu \mathrm{l}$ of air before moving to the elution well. Different volumes of elution buffer (50-mM HEPES, $\mathrm{pH} 7.5 ; 0.5-\mathrm{M} \mathrm{NaCl} ; 0.5-\mathrm{M}$ imidazole) were tested in a common program (aspirated, $60 \mu \mathrm{l} / \mathrm{s}$; dispensed, $15 \mu \mathrm{l} / \mathrm{s}$ ). Protein content was measured after each cycle. Protein bound, cumulative yield and noneluted protein were plotted as a function of the elution cycle. All samples were run in triplicate.

\section{Effective binding capacity}

Effective binding capacity, defined as the maximum achievable yield, was measured by running the full purification method for different target proteins. The purification method was comprised of an equilibration

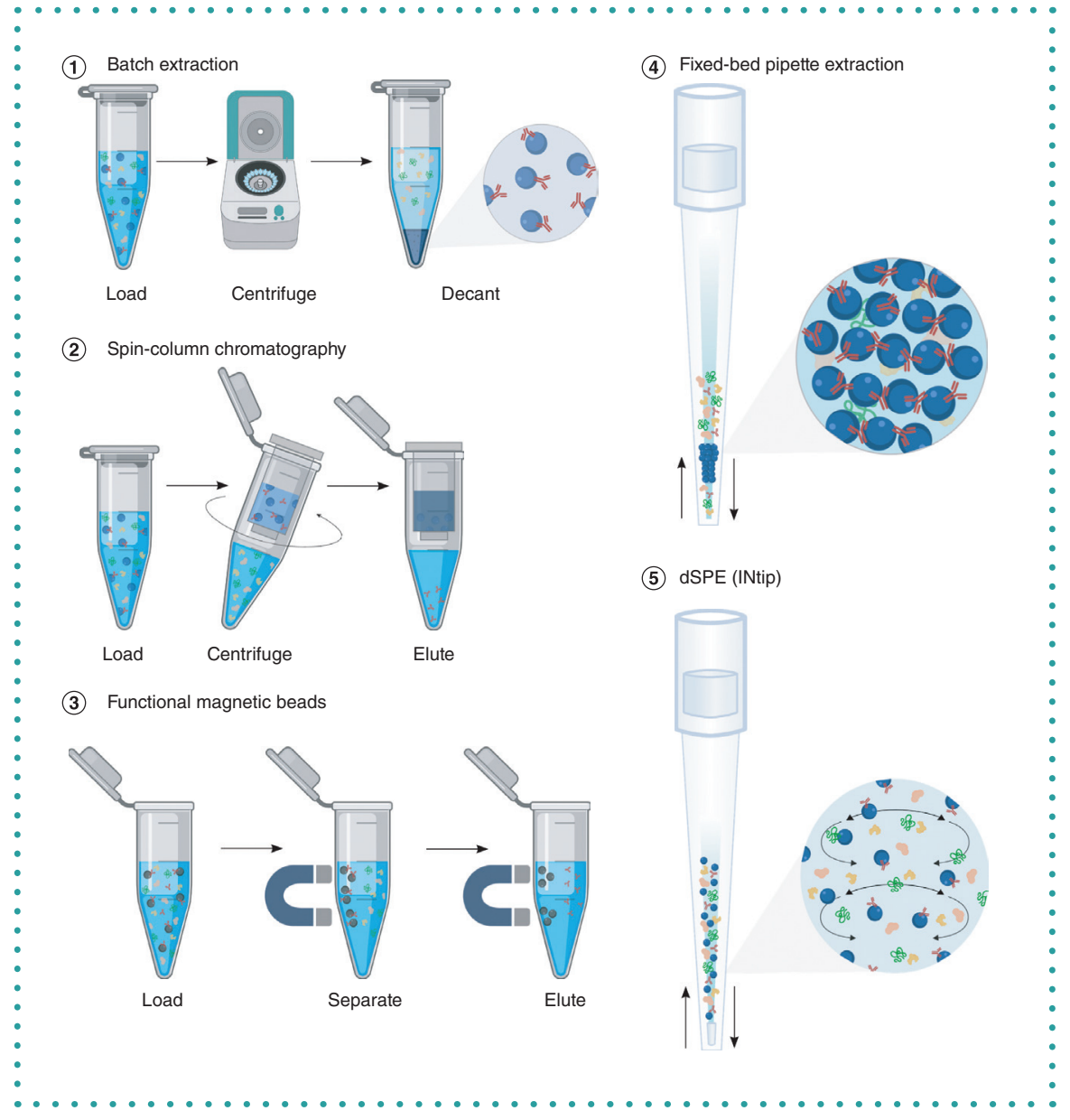

step (3 cycles), sample binding step (20 cycles), three wash steps ( 3 cycles each) and two elution steps (5 cycles each), totaling $72 \mathrm{~min}$. Protein was measured in each well. In addition to defined concentrations of $\mathrm{His}_{6}$ tagged target, the sample also contained $1.5-8.5 \mathrm{mg} / \mathrm{ml}$ of bacterial lysate, comprised of an array of nonspecific protein, lipids, nucleic acids and cellular metabolites. Eluted protein was measured by absorbance at $280 \mathrm{~nm}$ and the results combined to determine total protein eluted. Percent yield and absolute yield were plotted as a function of total target protein in the starting material.

\section{Effective dissociation constant \\ determination}

The effective dissociation constant $\left(K_{\mathrm{d}}\right)$ was determined by measuring the amount of protein eluted per gram of resin at different concentrations of free protein in the sample. Free protein was measured by absorbance at $280 \mathrm{~nm}$ before and after sample binding. Protein eluted was also measured by absorbance at $280 \mathrm{~nm}$. Protein eluted per gram of resin versus concentration of free protein was plotted and fitted with the single-site Langmuir isotherm (Equation 2 ) to yield $Q_{\max }$ and $K_{\mathrm{d}} \cdot Q_{\mathrm{e}}$ was defined as the milligrams of protein eluted per gram of resin, and $C_{e}$ was the concentration of free protein $(\mathrm{mg} / \mathrm{l}) . Q_{\max }$ is defined as the maximum amount of protein eluted from the column, and $K_{\mathrm{d}}$ is the concentration of free protein in solution at which half of the $Q_{\max }$ is eluted.

$Q_{e}=\frac{Q_{\max } C_{e}}{K_{d}+C_{e}}$

(Equation 2)

\section{DISCUSSION \& RESULTS}

Binding profiles were first investigated for the effects of aspiration and dispense cycle number and time using both pure protein solutions and fortified cell lysates. Binding was consistent across both sample solutions and protein concentrations regardless of cell lysate. For all targets, binding was $>90 \%$ complete after 20 cycles, where each cycle included one aspiration and dispense step (Figure 2). Elution profiles were also explored 


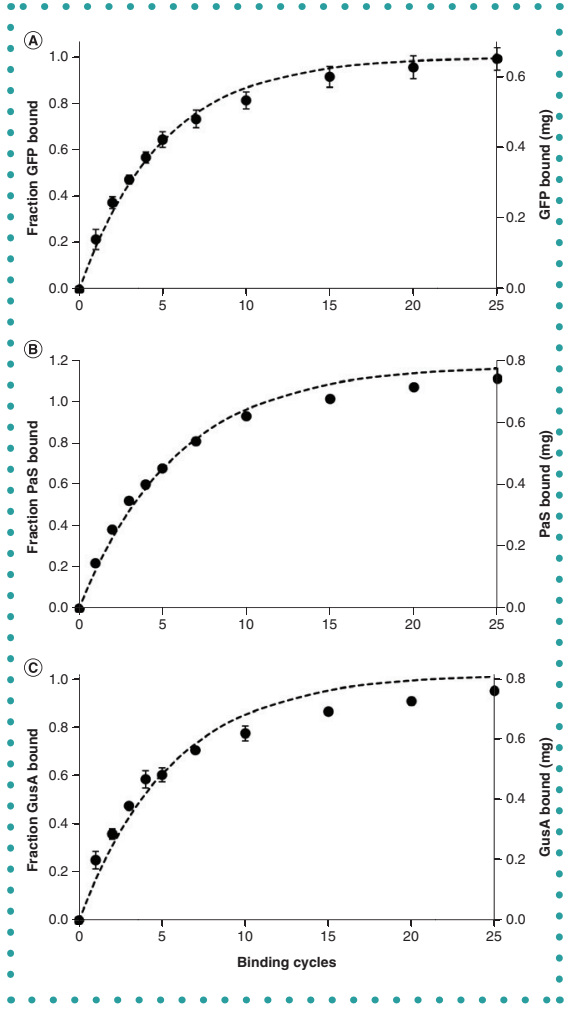

Figure 2. Binding dynamics of various proteins in dSPE pipette tips. (A) Recombinant PaS expressed and purified from Escherichia coli $(0.79 \mathrm{mg})$ binding to $25 \mu \mathrm{l}$ of XL.

(B) Recombinant GFP expressed and purified from E. coli $(0.66 \mathrm{mg})$ binding to $25 \mathrm{mg}$ of XL. (C) Recombinant GusA expressed and purified from $E$. coli $(0.77 \mathrm{mg})$ binding to $25 \mathrm{mg}$ of XL. Sample loading wells contained $825 \mu \mathrm{l}$ of total volume. Each binding cycle aspirated and dispensed $800 \mu \mathrm{l}$ at $60 \mu \mathrm{l} / \mathrm{s}$ and $15 \mu \mathrm{l} / \mathrm{s}$. Protein content was measured by A280 (NanoDrop) using calculated extinction coefficients [17]. Data were fitted to a single exponential growth function (Equation 1).

dSPE: Dispersive solid-phase extraction; GFP: Green fluorescent protein;

GusA: Beta-glucuronidase; PaS: Pseudomonas aeruginosa arylsulfatase; $\mathrm{XL}: \mathrm{Ni}^{2+}$ Sepharose ${ }^{\mathrm{TM}}$ excel.

by altering the elution volumes and number of fractions. Typically, elution in the lowest volume possible would yield the highest concentrations, whereas larger volumes would increase yields while decreasing protein concentration. To allow resin to settle between steps, a delay was added after aspiration and before dispensing on the final cycle of each load and wash step. Elution volumes $(200-800 \mu \mathrm{l})$ had no impact on the final protein yield (Supplementary Figure 1). Elution of protein was nearly complete after two cycles for all volumes (Supplementary Figure 2). Although the cycle number

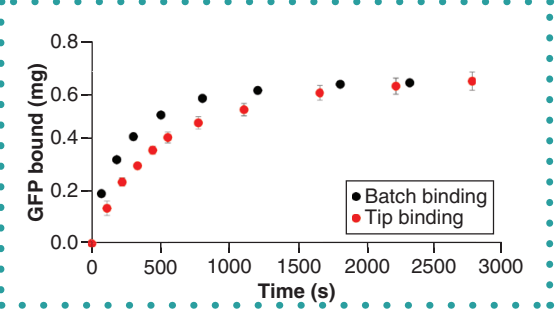

Figure 3. Comparison of batch and dSPE tip sample binding. Both batch (black) and dSPE tips (red) were run with $0.66 \mathrm{mg}$ of recombinant GFP. Protein bound was measured by subtracting the protein remaining in solution from the initial value.

dSPE: Dispersive solid-phase extraction; GFP: Green fluorescent protein.

suggests no impact on elution efficiency, reduced volumes also result in shorter cycle times and more concentrated product. Thus, a low volume $(300 \mu \mathrm{l})$ was chosen for further work.

To provide a measure of predicative capability in the purification protocol, the kinetics of protein binding in dSPE tips were investigated. Simply, binding of a ligand to its receptor depends on the concentration of the ligand, the receptor and the rate constants for binding (the on rate) and dissociation (the off rate), which combined describe an equilibrium constant $\left(K_{\mathrm{a}}\right.$ or $K_{\mathrm{d}}$ ). The actual story is more complicated, involving movement of solution molecules from the bulk phase to surface layers, two-dimensional diffusion and - in the case of porous resins - diffusion into the resin itself, all of which usually get invisibly amalgamated into the rate constants. Because dSPE tips represent a well-mixed system, binding can be modeled as a bimolecular reaction. This is most evident when looking at the effect of time (cycle number) on sample binding (Figure 2). A single exponential function $(A+B \rightarrow A B)$ fits the data well. Moreover, the rate of binding was comparable to batch chromatography where resin was mixed with protein on a RotoFlex (Figure 3). Notably, binding in dSPE tips lags relative to batch. This lag might be attributed to the mixing mode of the batch method, where the total sample volume mixes with total resin during the binding reaction. In contrast, with aspiration and dispensing, the fractional volume of protein solution accessible to the resin increases as it is aspirated and then decreases as the solution is dispensed, creating a time-averaged interaction that is a function of the aspiration and dispense rates. For simplicity of calculation, we have assumed a contact time equal to the full cycle length (110 s).

In dispersive tips, $50 \%$ of sample was bound after four cycles. The rate of binding drops over subsequent cycles (>15 cycles), deviating from the exponential binding function. This deviation is more pronounced for larger proteins or protein complexes, such as GusA ( 284-kDa tetramer) and PaS ( 61-kDa monomer), likely because the exponential model treats binding as an interaction between a ligand and a solid surface, whereas the porous agarose resin has $\mathrm{Ni}^{2+}$ of varying accessibility. The accessible surface ions are rapidly bound, but less accessible ions in the pores are occupied more slowly. This might account for the disparity between the observed fraction bound and the model at longer cycle times. Coincidentally, GFP (27-kDa monomer) had the lowest fraction of resin bound measured and the best fit to the exponential model, further suggesting that the difference in observed binding might be due to differential rates of binding.

In the initial stages of the reaction, binding is dominated by the reaction between surface $\mathrm{Ni}^{2+}$ and the protein solution, and the initial rates were determined from the first four cycles fit with the single exponential function (Equation 1). The $k_{\text {obs }}$ values $\left(2.1 \times 10^{-4}\right.$ to $\left.1.1 \times 10^{-3} \mathrm{~s}^{-1}\right)$ plotted as a function of initial protein concentration show a linear relationship (Figure 4), where the slope $\left(3.8 \pm 0.1 \times 10^{1} \mathrm{M}^{-1} \mathrm{~s}^{-1}\right)$ represents the bimolecular rate constant, and the Y-intercept $\left(3.1 \pm 1.9 \times 10^{-5} \mathrm{~s}^{-1}\right)$ represents the off rate $\left(k_{\text {off }}\right)$. The calculated $K_{d}$ value of $8.0 \pm 0.3 \times 10^{-7} \mathrm{M}$ compares well with previous measurements of the affinity of histidine-tagged fluorescent moieties for $\mathrm{Ni}^{2+}-$ nitrilotriacetic acid resins $(0.4-1.0 \mu \mathrm{M})$ by fluorescence anisotropy $[18,19]$.

In an effort to determine an effective binding capacity and thus the effective dissociation constant, the amount of purified material recovered over two elution steps was measured by absorbance at $280 \mathrm{~nm}$ for a range of initial protein amounts (0.20-5.0 mg). Absolute yields ranged from 0.19 to $2.0 \mathrm{mg}$, which translates to $99 \%$ at low loading down to $40 \%$ at the highest load. The dSPE tip remained effective ( $\geq 75 \%$ yield) for GFP up to $2.0 \mathrm{mg}$. There are several possible reasons for this, 


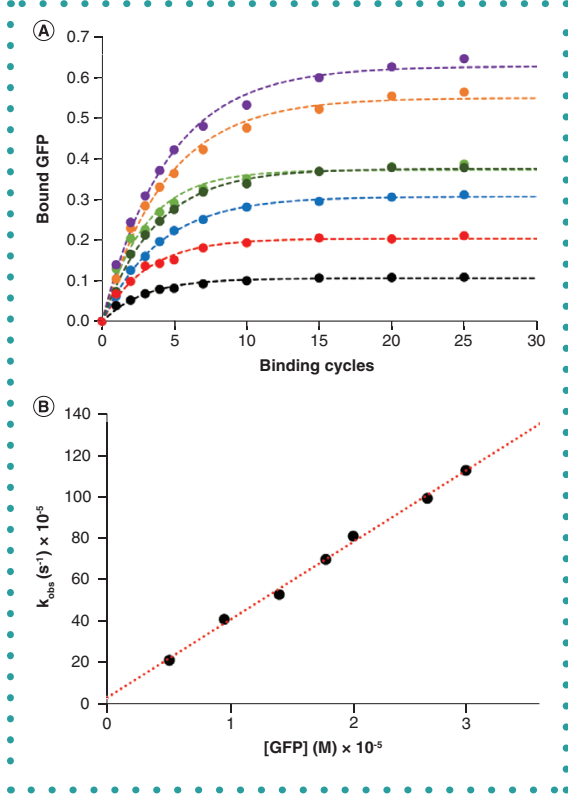

Figure 4. Determination of bimolecular rate constants for GFP binding to XL. (A) Kinetic data of various concentrations of GFP binding to $X L$ over 25 binding cycles (purple, $0.66 \mathrm{mg}$; orange, $0.59 \mathrm{mg}$; green, $0.45 \mathrm{mg}$; olive, $0.40 \mathrm{mg}$; blue, $0.32 \mathrm{mg}$; red, $0.22 \mathrm{mg}$; black, $0.12 \mathrm{mg}$ ). (B) Determination of bimolecular rate constant. Observed rate constant $\left(k_{\text {obs }}\right)$ values were determined from exponential fits of the first four binding cycles. The measured bimolecular rate constant was $3.8 \pm 0.1 \times 10^{1} \mathrm{M}^{-1} \mathrm{~s}^{-1}$ with an observed $k_{\text {off }}$ of $3.1 \pm 1.9 \times 10^{-5} \mathrm{~s}^{-1}$.

GFP: Green fluorescent protein; $\mathrm{XL}: \mathrm{Ni}^{2+}$ Sepharose ${ }^{\mathrm{TM}}$ excel.

including nearing saturation, occlusion of binding sites and differential loss of protein to dead volume.

The pattern of yield loss past a threshold protein load was consistent for all three proteins, although the inflection point occurred at different concentrations depending on the protein. The size of the tagged protein was inversely proportional to the molar amount eluted - perhaps larger proteins (GusA) occupy more surface area, thus blocking a larger fraction of $\mathrm{Ni}^{2+}$ per protein. To test this, an estimated minimum Stokes radius was calculated based on molecular weight and plotted versus the maximum concentration effectively bound (Supplementary Figure 3) calculated from $Q_{\max }$. The relationship between the Stokes radius and effective binding concentration would not be predicted to be linear, and this was observed $(n=3)$. Generating a standard curve relating molecular weight to effective binding concentration would be useful, as it would provide a basis for predicting

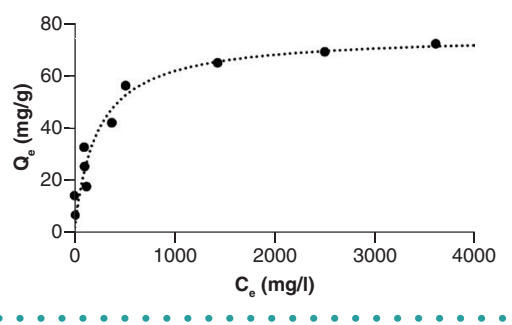

Figure 5. Determination of the effective dissociation constant for GFP and XL. $Q_{\mathrm{e}}$ data (black) are calculated as milligrams of eluted GFP per gram of resin. Fitted line (dashed) is calculated from the Langmuir isotherm (Equation 2), yielding a $K_{\mathrm{d}}$ value of $8.2 \pm 2.3 \times 10^{-6} \mathrm{M}$. GFP: Green fluorescent protein; $\mathrm{XL}: \mathrm{Ni}^{2+}$ Sepharose ${ }^{\mathrm{TM}}$ excel.

yield prior to experimentation. Studies are ongoing to determine if a standard curve relating molecular weight to binding capacity is feasible.

The value of maximum binding and elution $\left(Q_{\max }\right)$ was used to calculate $K_{\mathrm{d}}$ values for individual proteins and resins (Table 2). Notably, the effective $K_{d}$ for GFP $\left(8.2 \pm 2.3 \times 10^{-6} \mathrm{M}\right)$ is different from our previously calculated $K_{d}$ of $8.0 \pm 0.3 \times 10^{-7}$ $\mathrm{M}$ (Figure 5). The discrepancy may be due to the effective value being determined by the amount of protein in the eluate. Protein losses due to dead volume in the resin and frit have a greater impact on more concentrated eluate. Additionally, GFP is known to oligomerize at high concentrations $[20,21]$. Inconsistent binding ratios of GFP:histidine tag may artificially inflate the effective $K_{\mathrm{d}}$. The effective $K_{\mathrm{d}}$ value and $Q_{\max }$ can be used to compare proteins on a given resin or to select an appropriate resin for a given protein. This is demonstrated when comparing the binding and elution of GFP to $\mathrm{XL}$ and FF (Figure $6 \&$ Supplementary Figure 4). The effective $K_{\mathrm{d}}$ and $Q_{\max }$ values in the case of $\mathrm{XL}$ $\left(8.2 \pm 2.3 \times 10^{-6} \mathrm{M}\right.$ and $76 \pm 5.7 \mathrm{mg} / \mathrm{g}$, respectively) are about half of those observed for

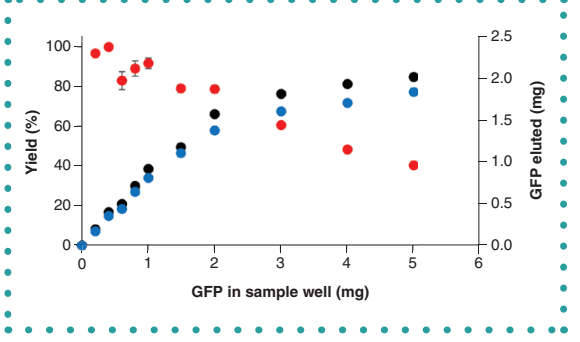

Figure 6. Profile of recovered GFP in total yield (red) and recovered mass as a function of initial sample available XL. The total yield of the purification (red) ranged from 99 to $40 \%$. Amount of protein eluted in the first of two elutions $(\mathrm{mg})$ steps is depicted in blue $(0.17-1.8 \mathrm{mg})$. The total protein recovered (black) ranged from 0.19 to $2.0 \mathrm{mg}$. GFP: Green fluorescent protein; $\mathrm{XL}: \mathrm{Ni}^{2+}$ Sepharose ${ }^{\mathrm{TM}}$ excel.

$\mathrm{FF}\left(2.3 \pm 0.3 \times 10^{-5} \mathrm{M}\right.$ and $120 \pm 7.7 \mathrm{mg} / \mathrm{g}$, respectively).

\section{CONCLUSION}

Overall performance of the INtip purification was excellent. Protein purity was $>95 \%$ with $10 \%$ higher yields than from spin column purification $(89 \% \pm 3.8$ vs $80 \% \pm 4.8 ; p=0.04)$ (Figure 7). Effective binding capacity was observed to be over $40 \mu \mathrm{g} / \mu \mathrm{l}$ resin for $X L$ for each of the proteins tested. This value is higher than the dynamic binding capacity reported by GE Healthcare $(10 \mu \mathrm{g} / \mu \mathrm{l}$ at $10 \%$ breakthrough), but specific capacity is protein dependent. When considering an $80 \%$ yield of eluted protein, resin capacities for the given proteins were $40 \mu \mathrm{g} / \mu \mathrm{l}$ resin (GFP), $32 \mu \mathrm{g} / \mu \mathrm{lresin}(\mathrm{PaS})$ and $25 \mu \mathrm{g} / \mu \mathrm{l} \mathrm{resin}$ (GusA). As was expected from the GE Healthcare reported capacities, FF had higher binding capacities, and resin capacities were in line with manufacturer guidelines (GFP $44 \mu \mathrm{g} / \mu$ lat $88 \%$ yield). In contrast to spin columns and magnetic bead purification, we observe high yields and purity using INtip affinity chromatography.
Table 2. Measurement of effective dissociation constant and effective binding capacity for various proteins in dSPE Ni Sepharose excel tips.

\begin{tabular}{|l|l|l|} 
Protein of interest & \multicolumn{1}{|l}{ Effective $K_{\mathrm{d}}(\mu \mathrm{M})$} & $Q_{\max }(\mathbf{m g} / \mathrm{g}$ resin) \\
\hline GFP & $8.2 \pm 2.3$ & $76 \pm 5.7$ \\
\hline PaS & $1.7 \pm 0.5$ & $49 \pm 3.2$ \\
\hline GusA & $1.3 \pm 0.2$ & $60 \pm 3.1$ \\
\hline
\end{tabular}

dSPE: Dispersive solid-phase extraction; GFP: Green fluorescent protein; GusA: Beta-glucuronidase; PaS: Pseudomonas aeruginosa arylsulfatase. 


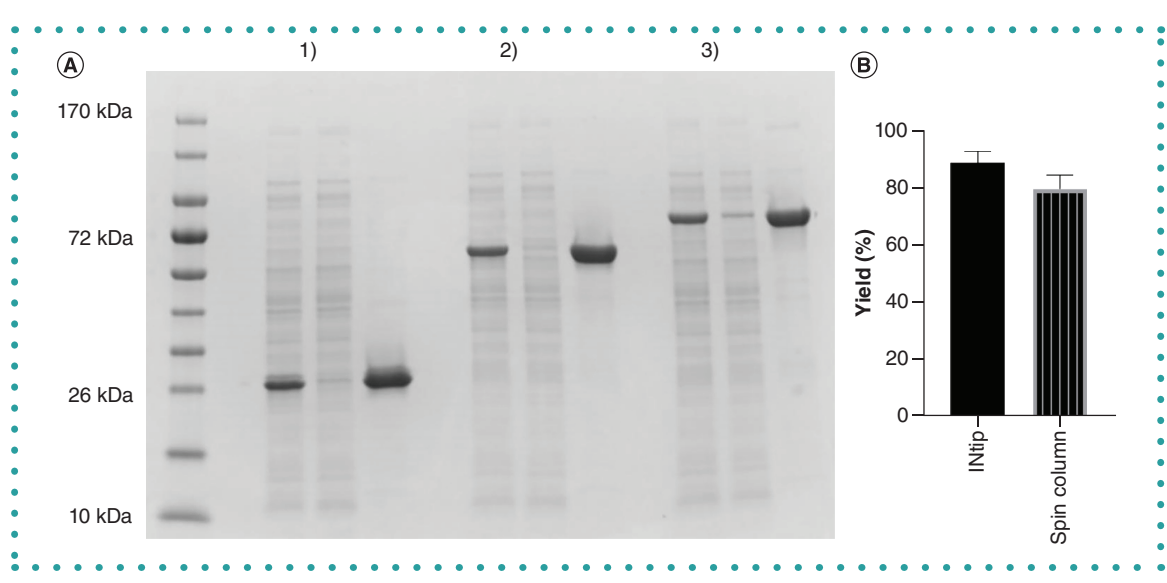

Figure 7. INtip purification of proteins. (A) SDS-PAGE gel showing INtip purification of three proteins $(0.6 \mathrm{mg})$ presented in the study. From left to right (marker Fisher BioReagents EZ-Run Prestained Rec Protein Ladder). 1. GFP in cell lysate prior to purification, flowthrough after sample loading and eluate $(0.56 \mathrm{mg}) .2$. PaS in cell lysate prior to purification, flowthrough after sample loading and eluate $(0.58 \mathrm{mg})$. 3. GusA in cell lysate prior to purification, flowthrough after sample loading and eluate $(0.55 \mathrm{mg})$. (B) Comparison of INtip and spin column purification of GFP using $25 \mu \mathrm{l}$ of XL. GFP: Green fluorescent protein; GusA: beta-Glucuronidase; INtip: in a pipette tip; PaS: Pseudomonas aeruginosa arylsulfatase; $\mathrm{XL}: \mathrm{Ni}^{2+}$ Sepharose ${ }^{\mathrm{TM}}$ excel.

Moreover, the low cost and ability to scale along with automation suggest that INtip purification could play an increasingly important role for HTP affinity chromatography. Simple steps (equilibration, sample binding, wash and elution) integrate with the strengths of automated platforms. Moreover, these strengths allow for coupling multiple purification regimens, suggesting extended applications for both single- and doubletagged proteins. Affinity purification via the INtip platform matches or exceeds the four current technologies.

\section{FUTURE PERSPECTIVE}

Batch chromatography remains a widely used technique for processing large numbers of samples. Unlike batch chromatography, outside of initial setup of the plate, the dSPE tip method requires few if any manual steps (spin down is eliminated), and blowout steps between wells minimize carryover. As with batch chromatography, dSPE tips suffer little or no backpressure. This contrasts with fixed-bed resins in pipette tips. Upon the addition of a top filter to retain the resin, there is a noticeable increase in backpressure that necessitates lower aspiration and dispense speeds (data not shown). The lower backpressure, ability to translate between automation methods and high degree of reproducibility are advantageous for dispersive extraction. One drawback for the dispersive approach is the inability to accurately model flow rates for translation to traditional fast protein liquid chromatography purification. The complicated residence time calculations due to ever-changing volumes during aspiration and dispense cycles lower theoretical plate numbers.

Dispersive extraction technology excels in the rapid functional screening of resins or small-scale ( 0.1-2 mg) protein purification for early discovery. The ease of scalability and automation-friendly nature make dSPE tips attractive for an abundance of sample numbers (1-96+). The push toward high-throughput processing of biological samples in industrial purifications suffers from a dearth of inexpensive and reliable automation-friendly affinity techniques. The addition of centrifuges, robotic arms or grippers and/or magnetic plates, as well as programming the liquid handlers, are continuous challenges in high-throughput applications. Major processes such as batch, column and spin column chromatography suffer from required manual steps, inability to process multiple simultaneous samples or poor yields. This paper presents an automation-friendly dispersive technology capable of high throughput and excellent yields. Moreover, dSPE tips can be utilized across multiple automation platforms ranging in capabilities and price. By placing a commonly used affinity resin in dSPE tips, we hope to enhance affinityrelated capabilities for automated liquid handling devices in addition to providing improved accessibility to these automated platforms for protein purification for academic and industrial labs alike.

\section{SUPPLEMENTARY DATA}

To view the supplementary data that accompany this paper please visit the journal website at: www.future-science. com/doi/suppl/10.2144/btn-2019-0140

\section{AUTHOR CONTRIBUTIONS}

PA Kates, JJ Tomashek and LA Lee helped in the design of this project. PA Kates and DA Miles performed the experimentation. PA Kates, JJ Tomashek and LA Lee analyzed the associated data. PA Kates wrote the draft of this manuscript. JJ Tomashek and LA Lee provided input and contributed to the writing of the manuscript.

\section{ACKNOWLEDGMENTS}

The authors wish to thank $\mathrm{G}$ Horvath for his assistance in protein production. The authors also wish to thank $\mathrm{K}$ Milloy for her work on Figure 1.

\section{FINANCIAL \& COMPETING INTERESTS DISCLOSURE}

All authors are employed by Integrated Micro-Chromatography Systems, Inc. The authors have no other relevant affiliations or financial involvement with any organization or entity with a financial interest in or financial conflict with the subject matter or materials discussed in the manuscript apart from those disclosed.

No writing assistance was utilized in the production of this manuscript.

\section{OPEN ACCESS}

This work is licensed under the AttributionNonCommercial-NoDerivatives 4.0 Unported License. To view a copy of this license, visit http://creativecommons.org/licenses/ by-nc-nd/4.0/

\section{REFERENCES}

Papers of special note have been highlighted as: $\bullet$ of interest

1. Van Helden PD. Use of Elutips to purify DNA BT - new nucleic acid techniques. In: New Nucleic Acid Techniques. Walker JM (Ed.) 61-67 Humana Press, Clifton, NJ (1988).

2. Luan P, Lee S, Arena TA et al. Automated high throughput microscale antibody purification workflows for accelerating antibody discovery. mAbs 10(4), 624-635 (2018).

- Tip columns are used in a high-throughput environment to purify antibodies.

3. Chhatre S, Titchener-Hooker NJ. Review: microscale 
methods for high-throughput chromatography development in the pharmaceutical industry. J. Chem. Technol. Biotechnol. 84(7), 927-940 (2009).

4. Łącki KM. High-throughput process development of chromatography steps: advantages and limitations of different formats used. Biotechnol. J. 7(10), 1192-1202 (2012).

- The author describes the strengths and weaknesses of various purification protocols with regard to high-throughput automation systems.

5. Guan H, Brewer WE, Garris ST, Craft C, Morgan SL. Multiresidue analysis of pesticides in fruits and vegetables using disposable pipette extraction (DPX) and micro-luke method. J. Agric. Food Chem. 58(10), 5973-5981 (2010).

6. Bordin DCM, Alves MNR, de Campos EG, De Martinis BS. Disposable pipette tips extraction: fundamentals, applications and state of the art. J. Sep. Sci. 39(6), 1168-1172 (2016).

7. Mastrianni KR, Metavarayuth K, Brewer WE, Wang Q Analysis of $10 \beta$-agonists in pork meat using automated dispersive pipette extraction and LC-MS/MS. J. Chromatogr. B. 1084, 64-68 (2018).

8. Islas G, Ibarra IS, Hernandez P, Miranda JM, Cepeda A. Dispersive solid phase extraction for the analysis of veterinary drugs applied to food samples: a review. Int J. Anal. Chem. 2017, 8215271 (2017).

9. Hu X-Z, Chen M-L, Gao Q, Yu Q-W, Feng Y-Q. Determination of benzimidazole residues in animal tissue samples by combination of magnetic solid-phase extraction with capillary zone electrophoresis. Talanta $89,335-341$ (2012).
10. Reyes-Gallardo EM, Lucena R, Cárdenas S, Valcárcel M. Dispersive micro-solid phase extraction of bisphenol A from milk using magnetic nylon 6 composite and its final determination by HPLC-UV. Microchem. J. 124, 751-756 (2016)

11. Ying $Y-F$, Wu $Y-L$, Wen $Y$, Yang $T$, Xu X-Q, Wang $Y-Z$. Simultaneous determination of six resorcylic acid lactones in feed using liquid chromatography-tandem mass spectrometry and multi-walled carbon nanotubes as a dispersive solid phase extraction sorbent. J. Chromatogr. A 1307, 41-48 (2013).

12. Milheiro J, Ferreira LC, Filipe-Ribeiro L, Cosme F, Nunes FM. A simple dispersive solid phase extraction clean-up/concentration method for selective and sensitive quantification of biogenic amines in wines using benzoyl chloride derivatisation. Food Chem. 274 110-117 (2019).

13. Mastrianni KR, Kemnitzer WE, Miller KWP. A novel, automated dispersive pipette extraction technology greatly simplifies catecholamine sample preparation fo downstream LC-MS/MS analysis. SLAS Technol. TransI. Life Sci. Innov. 24(1), 117-123 (2018).

- Use of dispersive solid-phase extraction tips on an automated platform demonstrates low coefficients of variation.

14. Mullis BT, Hwang S, Lee LA et al. Automating complex, multistep processes on a single robotic platform to generate reproducible phosphoproteomic data. SLAS Discov. doi:10.1177//2472555219878152 (2019) (Epub ahead of print).

15. Herrera-Herrera AV, Asensio-Ramos M, Hernández-Borges J, Rodríguez-Delgado MÁ. Dispersive liquid-liquid microextraction for determination of organic analytes.
TrAC Trends Anal. Chem. 29(7), 728-751 (2010)

16. Ngaosi N, Seebunrueng $K$, Srijaranai S. In-syringe reversed dispersive liquid-liquid microextraction coupled to high performance liquid chromatography for the determination of sulfonylurea herbicide residues in cereal samples. Anal. Methods 8(21), 4254-4262 (2016).

17. Gill SC, von Hippel PH. Calculation of protein extinction coefficients from amino acid sequence data. Anal. Biochem. 182(2), 319-326 (1989).

18. Kapanidis AN, Ebright YW, Ebright RH. Site-specific incorporation of fluorescent probes into protein: hexahistidine-tag-mediated fluorescent labeling with $\mathrm{Ni}(2+)$ :nitrilotriacetic acid (n)-fluorochrome conjugates. J. Am. Chem. Soc. 123(48), 12123-12125 (2001).

- The authors offer comparative determination of $\mathrm{His}_{6}{ }^{-}$ tagged binding affinities for $\mathrm{Ni}$ resins.

19. Dorn IT, Neumaier KR, Tampé R. Molecular recognition of histidine-tagged molecules by metal-chelating lipids monitored by fluorescence energy transfer and correlation spectroscopy. J. Am. Chem. Soc. 120(12), 2753-2763 (1998).

20. Vámosi G, Mücke N, Müller G et al. EGFP oligomers as natural fluorescence and hydrodynamic standards. Sci. Rep. 6, 33022 (2016)

21. Zacharias DA, Violin JD, Newton AC, Tsien RY. Partitioning of lipid-modified monomeric GFPs into membrane microdomains of live cells. Science 296(5569), 913-916 (2002). 